\title{
Challenges to Autism Research
}

\author{
Dame Stephanie Shirley
}

J R Soc Med 2005;98:523-525

Like many parents of a child with autism, the disorder has come to dominate my life. For 35 years I was involved with the daily experiences of caring, then with support services, schools and various strategic initiatives in the autism sector. But, perhaps inevitably, I am nowadays focused on research into causes. I do this via NAAR [the National Alliance for Autism Research] and its global affiliates. I try to work always with respect: respect for people with autism who, like my late son, are without speech, epileptic and with profound learning disabilities; also respect for those high performing individuals at the other end of the spectrum who denounce the search for causes.

When as a child, I found myself lost and frightened in a park, I came across one of those maps on a notice board with a big arrow pointing, 'You are here'. Awesome! How did they know? In research, we start from where we are, identify some landmarks and then follow a path to where we want to be in the future.

I finally got my own notice board with an arrow on it. Last year, my charitable The Shirley Foundation commissioned Kate Egan to carry out a global review of published material on research into the causes of autism. ${ }^{1}$ My acknowledgement underlines how often we need to work cross-discipline, inter-disciplinary, multi-disciplinary. It seems obvious and yet it is funny how often we forget to talk to one another. My first piece of advice to researchers is to try not to duplicate what has already been done. And publish what you do do. It can be important to know that something did not work and, as James Joyce put it, 'mistakes are the portals of discovery'. So, publish or perish.

Researchers can take comfort in the title of this paper. For the flipside of any challenge is an opportunity. They call on different skills so there is potential for many people to have the beautiful but frightening excitement of being the first to know something. Nobel Laureate Richard Feynman wrote in 1996:

'The worthwhile problems are the ones you can really solve or help solve, the ones you can really contribute something to. A problem is grand in science if it lies before us unsolved and we see some way to make a little headway into it'.

Chair of The Shirley Foundation, Henley on Thames, Oxfordshire RG9 2NA, England

E-mail: steve@steveshirley.com
When my son was born in 1963, autism was considered a rare disorder. Perhaps the most significant challenge to the autism research community stems from the apparently rapid increase in the number of people with autism. Worldwide a new case of autism is diagnosed nearly every 20 minutes. Such a rapid increase in numbers explains autism's poor funding and the unacceptable waiting times for services.

So the first challenge to autism research is to account for this change properly. Certainly the face of autism has changed, but no one knows whether the increase is due to more sensitive measurement, redefinition, or a true increase in the disorder. We know so little about it. It is a major obstacle to progress that diagnosis continues to rely on behaviour rather than basic biology.

So the second challenge is how to reliably diagnose autism and as early as possible. Children with an autistic spectrum disorder (ASD) are not all the same. How can we reliably distinguish between different patterns or stages of ASD and related developmental problems? How do we separate the developmentally delayed ('boys are always slow in talking') from the disabled; and the disabled from the more specifically autistic? This issue confounds many experiments which have control groups of typical children whereas what is needed are subjects with similar mental capabilities, epilepsy, etc., but without autism.

There is a known genetic component. Yet the unravelling of this is one of the greatest challenges we face. Many people have emphasized the need to obtain genetic samples of carefully diagnosed and characterized subjects - families in which there are several affected individuals, ideally over several generations. Gene identification will probably require thousands of families. We also need a global, standardized autism twin registry.

The third challenge to autism research is to answer the question 'is there one disorder or are there many separate but related disorders or alternative expressions of symptoms?'. Instead of working with apples and oranges, we want to be able to work with different strains of apples, eventually just different apples.

How do we identify the susceptibility genes? I am reminded of Agatha Christie's Murder on the Orient Express where no single person was guilty: they were all guilty, together they killed the victim. Of course, I use the term guilty here metaphorically - no gene is guilty - it is no one's fault. I know how corrosive blame is because in the 
early days of autism the mother was blamed for the way the child developed. And there are still worldwide remnants of such thinking, even in central Europe. So how should we approach our task in different societies? We fail to distinguish core attributes if actually they are cultural. Asian cultures consider eye contact to be impolite, for instance; and some questions used in diagnosis ask about children's response to their birthday party - a celebration not practised in many parts of the world. Is it enough to refer to people with autism as being 'exceptional' and with a 'developmental disorder'?

I pose the questions but do not have any answer.

And what do all these genes do to the brain? Which leads us to our fourth challenge. To learn to apply the tremendous advances in neuroscience to understanding and treating autism by improving interventions and treatments. What is different about the autistic brain? The susceptibility genes act by modifying the development of neural systems. Imaging technologies have made a tremendous difference to neuroscience. But progress with children with autism has been slow. This is partly because imaging children requires a level of compliance and patience, sometimes difficult even for normal adults, much less vulnerable children. Imaging technologies (or it could be methodologies) that worked for children with autism would significantly advance our understanding of their altered information processing.

An extension of this challenge is that the few existing brain banks provide only limited tissue of quality and access: progress is hampered by the shortage of post-mortem brains - either from those with autism, or for use in control groups. Researchers have my son's brain. And they will have mine. Human brains are the world's most precious resource. The cost of brain banking has come down, so it is largely staff costs - to administer the registrations and make best use of the actual donations (all the while being compassionate and professional throughout the grieving process).

Challenge five comes back to my own discipline of information technology. How do we bring resources and information together in an integrated strategy? The Human Genome Project involves scientists from all over the world networking together to share resources, data and technologies. Similar strategies are probably necessary to address the complex biology of the brain. This work has already begun in autism research as people work from centres of excellence and multi-site, international programmes scan for susceptibility genes. Information technology is powerful in drawing together data sets and mining down for their secrets.

My personal change of focus from intervention to cause brings me to the sixth challenge. As far as treatment goes, how does one optimize the current interventions and integrate new research into clinical applications? It is important to have a concerted and vigorous effort to benchmark interventions, perhaps tailored to unique subsets of autism populations. The National Autistic Society is planning a major drive in this area. So is the American $\mathrm{NIMH}$, an outcome of the collaboration between biomedics and educators in recent years. Interventions are typically applied when children are pre-school or already in schoolrelatively late. Studies of the infant siblings of children with autism can effectively allow interventions for very young children. Advances in brain research which translate into meaningful clinical applications deliver answers and solutions to the community.

The supreme challenge in autism research, my final challenge, number seven, is the vulnerability of children during research, their inability to make autonomous decisions (legislation in Scotland is helpful with this issue), and the absolute right of affected families to confidentiality during the research process.

Thoughtful strategies to address these important issues must be integrated into every step of the research process. It is necessary (but not sufficient) for professionals to avoid confronting children much as they do a laboratory specimen. And particularly with children with autismeach is neither a miniature adult nor just a walking set of conditions. Paediatric ethics depends on genuine respect for children. We need to distinguish between parental permission, child assent, legal authorization and moral responsibility. And we must learn to listen to parents. A research worker may aspire to become a world expert in some aspect of the science. But most parents already are world experts in their own children. Parents need to play both formal and informal roles in the research process.

Although it is desirable to engage the biotechnology and pharmaceutical industries, most funding for research is likely to continue to come from the public sector. Early next year NAAR (UK) is mounting a Parliamentary lobby to increase the funding for research into the causes of autism - the first phase of an ongoing lobby to redress the disproportionate low spend in this area-compared with less common disorders. And to move autism permanently up the agenda in both the UK and in Brussels.

The public has been enormously engaged in issues such as MMR. Much of which has been misguided, hysterical, unhelpful. But MMR has engaged the public. And that is needed because autism is only one research area among many competing areas.

The days are long gone when findings arose from the lone scientist isolated in the laboratory. The most successful scientists are team workers. A recent study of Nobel Laureates found that they collaborated with colleagues more often than the non-prizewinner scientists who worked competitively. So I believe that the basis of real progress will come when people work cooperatively rather than 
competitively. Partnerships, alliances, associations, affiliates, consortia, networks are the laboratories of the 21 st century.

I conclude with two aspects of timing. My age gives me an urgency that youngsters lack but I have learnt 'urgent patience'. For research cannot be hurried. No matter how much money is allocated, the search for causes will still take years. But there are times when things are moving and times when they are not. There is a paradigm shift in medicine generally so there is a timeliness about autism research today. Science is always the art of the possible. And if people work on the main challenges to autism research, there are very good chances (perhaps as high as 1 in 10) of producing something that makes a real difference.
Note: This paper is based on my presentation to the RSM seminar coordinated together with the National Autistic Society in Manchester on 8 June 2005.

Dame Stephanie has invested $£ 35$ million in the autism sector, the last few years concentrating on research into causes. She is chair of The Shirley Foundation (which commissioned and funded Kate Egan's review referred to in the text). She is also a trustee of the National Alliance for Autism Research and chairs its UK affiliate NAAR (UK).

\section{REFERENCE}

1 Kate Egan. Autism: State of the Global Science. Oxfordshire: The Shirley Foundation (in press) 